\title{
FORMAÇÃO INOVADORA NO AGRONEGÓCIO: UMA EXPERIÊNCIA PIONEIRA EM EAD - REDE E-TEC BRASIL NO SENAR
}

\author{
BRASÍLIA/DF MAIO/2018
}

\begin{abstract}
Andreia Sardagna Sudoski - DOT DIGITAL GROUP - andreia.sudoski@dotgroup.com.br Karen Helena Bueno Lanfranchi - DOT DIGITAL GROUP - karen.lanfranchi@dotgroup.com.br Lizia Carbolin Martins - DOT DIGITAL GROUP - lizia.martins@dotgroup.com.br Maria Cristina Ferreira - SENAR - cristina.ferreira@senar.org.br

Patrícia Bernardo - DOT DIGITAL GROUP - patricia.bernardo@dotgroup.com.br Simone Soares Haas Carminatti - DOT DIGITAL GROUP - simone.carminatti@dotgroup.com.br Sônia Inez Grüdtner Floriano - DOT DIGITAL GROUP - sonia@dotgroup.com.br Valquiria Santos Segurado - DOT DIGITAL GROUP - valquiria.segurado@dotgroup.com.br
\end{abstract}

Tipo: Relato de Experiência Inovadora (EI)

Categoria: Métodos e Tecnologias

Setor Educacional: EDUCAÇÃO MÉDIA E TECNOLÓGICA

\begin{abstract}
RESUMO
Este artigo descreve a experiência pioneira e inovadora do SENAR, com a formação técnica gratuita em Agronegócio, na modalidade de EaD no formato híbrido/blended learning, que tem por objetivo oportunizar a formação técnica gratuita em Agronegócio para o público do meio rural em todo território brasileiro tendo por base os Referenciais Educacionais da instituição. Para tanto, o artigo está organizado em tópicos que apresentam, nesta ordem, as referências metodológicas para a prática, os profissionais envolvidos, o sistema avaliativo, além dos primeiros resultados, tanto em relação à sua operação quanto à avaliação de reação realizada pelos alunos
\end{abstract}

Palavras-chave: Formação Técnica; Agronegócio no SENAR; Inovação e Pioneirismo; Híbrido/Blended learning; EaD 


\section{Introdução}

O Agronegócio no Brasil é um setor em constante expansão, vem crescendo exponencialmente ano a ano em importância econômica nacional e no exterior. Estudos do sistema CNA, ICNA e SENAR apontam que o Brasil já é o segundo maior produtor mundial de alimentos e sua presença nos sistemas agroalimentares é mais do que estratégica, é indispensável. Internamente, as atividades produtivas desse setor têm impactado no crescimento de oferta de empregos, das exportações e do PIB. Parte dessa ascensão é resultado das inovações tecnológicas que envolvem novos procedimentos em grandes, médias e pequenas propriedades.

Esse cenário promissor também trouxe novos desafios para a profissionalização da mão de obra no campo. Tornaram-se necessárias iniciativas de formação que propiciem a aquisição de novas capacidades técnicas, por intermédio de metodologias dinâmicas e inovadoras, que conciliam o desenvolvimento de competências, habilidades e atitudes de acordo com o contexto e necessidades reais do público-alvo e do setor agropecuário brasileiro.

Atento às mudanças, o Serviço Nacional de Aprendizagem Rural (SENAR) aderiu ao programa Rede e-Tec Brasil do Ministério da Educação (MEC) instituído pelo Decreto no 7.589, de 2011. A Rede e-Tec faz parte do Programa Nacional de Acesso ao Ensino Técnico e Emprego (PRONATEC) e sua principal finalidade é promover de maneira democrática o acesso à Educação Profissional e Tecnológica (EPT), beneficiando-se das possibilidades de alcance e estratégias metodológicas da Educação a Distância (EaD).

Em 2014, pelo programa Rede e-Tec, o SENAR organizou a oferta do curso Técnico em Agronegócio, no formato de ensino híbrido ou blended learning. Para atender às especificidades do curso e à necessidade do público-alvo, foi desenvolvido um projeto educacional que contemple recursos tecnológicos e midiáticos, centrados na realidade dos estudantes, que residem ou trabalham no campo. O seu diferencial consiste na correlação teoria-prática por meio de uma metodologia inovadora, com processo de comunicação e interação planejado e sistemático, primando por interconexões entre todos os agentes diretos e indiretos, de modo a favorecer o processo, que media a construção do conhecimento dos alunos, tendo por apoio, infraestrutura virtual/presencial e convergência tecnológica.

Sendo assim, este artigo objetiva relatar o desafio de estruturar e de ofertar a formação técnica inovadora e pioneira para as pessoas do meio rural e apresentar os resultados dos três primeiros anos de projeto. Esse relato será embasado nos referenciais 
metodológicos do SENAR e na pesquisa de satisfação realizada com os alunos durante a realização dos módulos/semestres e unidades curriculares (UCs) do curso Técnico em Agronegócio.

\section{O SENAR}

Criado em 1991 pela Lei no 8.315, de 23 de dezembro do mesmo ano, e regulamentado pelo Decreto no 566, de 10 de junho de 1992, o Serviço Nacional de Aprendizagem Rural (SENAR), integrante do denominado Sistema "S", tem como principal objetivo organizar, administrar e executar em todo o território nacional a Formação Profissional Rural e a Promoção Social com ênfase nas características e demandas econômicas e sociais do campo. Suas atividades e cursos são oferecidos de forma gratuita a pessoas do campo que estejam envolvidas, direta ou indiretamente, com os processos produtivos agrossilvipastoris (florestas com agricultura e pecuária simultânea ou sequencial).

Por causa de sua capilaridade no meio rural, em 2010, inicia sua experiência de formação profissional, na modalidade Educação a Distância (EaD), ao oferecer cursos gratuitos livres de capacitação, via internet em larga escala, em parceria com o Instituto de Estudos Avançados (IEA), hoje com mais de 20 anos de experiência em planejamento, captação de alunos, produção, operacionalização e pesquisa de impacto. Atualmente, o IEA integra o DOT digital group com foco em negócios de Education Technology (EdTech) e Marketing Technology (MarTech). Em 2014, o SENAR, referência em Formação Profissional Rural (FPR), Formação Técnica (FT) e Promoção Social (PS), lança seu novo desafio: o primeiro curso gratuito Técnico de Nível Médio na modalidade a distância baseado no ensino híbrido denominado Curso Técnico em Agronegócio pela Rede e-Tec SENAR no Brasil, com parceria do IEA.

\section{Parceria SENAR e IEA}

A parceria de quase uma década entre o SENAR e o IEA teve início em 2010, por meio de um processo licitatório, com a oferta de cursos de formação inicial e continuada via internet. SENAR e IEA estruturaram uma equipe multidisciplinar - pedagogos, comunicadores, designers educacionais e multimídia, programadores, economistas, administradores, engenheiros agrônomos, veterinários, entre outros - com profissionais que realizam um trabalho de maneira integrada continuamente. Parte dessa equipe atua presencialmente nos polos de apoio e a outra parte atua virtualmente com apoio de tecnologias digitais de informação e comunicação (TDICs).

A equipe da Administração Central do SENAR é formada pelo Secretário Executivo, pelo Chefe do Departamento de Inovação e Conhecimento, pela Coordenadora de Educação Formal e por Assessores Técnicos, profissionais efetivos dedicados exclusivamente ao 
Curso Técnico em Agronegócio, com a responsabilidade de gerenciamento de todas as ações e tomadas de decisões junto à equipe do IEA e às Administrações Regionais do SENAR. As Administrações Regionais do SENAR atuam na oferta presencial do curso e realizam a gestão das atividades presenciais, das matrículas e das avaliações presenciais dos estudantes.

Os profissionais que atuam presencialmente, contratados pelo SENAR, são responsáveis pelo atendimento e acompanhamento aos alunos nos polos e compreendem: coordenador de polo, secretário escolar e/ou assistente de secretaria escolar, assistente técnico de laboratório de informática e tutores presenciais. Cada polo tem um tutor responsável pelo planejamento e aplicação de atividades teóricas e práticas, com atendimento para orientar, sanar dúvidas e incentivar a pesquisa. Além disso, organiza, aplica e corrige as avaliações presenciais e também controla a frequência e a participação dos alunos nas atividades presenciais.

A equipe virtual do IEA compõe as áreas de desenvolvimento, projetos e operacionalização do curso como um todo e é formada por: gestor de projetos, gestor de operações, coordenação pedagógica, consultoria educacional, analistas educacionais, designers educacionais, programadores, designers multimídia, analista acadêmico, analistas de informações, cientista de dados, revisores e monitores; e conta também com profissionais contratados por demanda, conteudistas e tutores a distância.

Grande parte do sucesso desse projeto deve-se ao trabalho integrado, colaborativo e em rede da Administração Central das Administrações Regionais do SENAR e da Coordenação do IEA, constituindo-se em uma inter-relação orquestrada entre todos os agentes envolvidos.

\section{Referenciais metodológicos para a prática pedagógica}

Como informado anteriormente, o curso Técnico em Agronegócio foi planejado e estruturado considerando o formato de ensino híbrido ou blended learning com o intuito de atender às especificidades do programa Rede e-Tec Brasil e às necessidades de formação técnica do público jovem e adulto do meio rural, conciliando a atuação profissional em suas propriedades. Moran (2017) corroborou com Valente (2015) ao entender o ensino híbrido como uma combinação de diferentes atividades presenciais e de tecnologias digitais de informação e comunicação em um processo continuum, pautada em um conteúdo que integra tempo, espaço e atividade, de modo a otimizar as potencialidades de cada uma. A ênfase é no processo ativo de aprendizagem com aporte na relação teoria-prática de construção individual e colaborativa do conhecimento. Os referenciais metodológicos do curso estão pautados em princípios 
pedagógicos e andragógicos, correlacionando teoria e prática com o intuito de possibilitar o desenvolvimento das competências, habilidades e atitudes, de forma contextualizada e voltada tanto para a prática profissional como para a vida dos educandos (SENAR, 2014).

Os princípios pedagógicos são pautados na concepção socioconstrutivista, na qual teoria e prática acontecem de forma indissociável. Assim, o contexto histórico, os conhecimentos prévios e a experiência dos educandos contribuem para um processo educativo interdisciplinar, flexível e integrador, na estrutura curricular e no processo de avaliação. Esses princípios estão de acordo com os pensamentos de Boiko e Zamberlan (2001), que defendem que a educação precisa ser entendida e estruturada como um processo dinâmico e dialético, considerando o contexto social, cultural, econômico, político dos educandos na relação teoria e prática.

Os princípios andragógicos, por sua vez, norteiam as ações pedagógicas no que tange a características como: responsabilidades laborais, pessoais e sociais, assim como necessidades de curto, médio e longo prazo de desenvolvimento de competências (saber), habilidades (saber fazer) e atitudes (querer fazer). Nesse sentido, esse curso projeta-se no desenvolvimento das competências comportamentais-atitudinais voltadas para a atuação diária dos Técnicos em Agronegócio, e das competências técnicocognitivas, que são os conhecimentos teóricos essenciais para as tomadas de decisões e estratégias diferenciadas no meio rural.

De acordo com Knowles \& Swanson (2015), precisamos considerar a necessidade pelo saber dos educandos, com foco no que ganharão ao aprender algo. Os educandos adultos relacionam suas experiências profissionais e pessoais no processo de aprendizado, ou seja, buscam relacionar o aprendizado com situações reais, necessitando da relação teoria-prática. Além disso, são responsáveis por sua própria vida, inclusive com o tempo e o ritmo do aprendizado. E suas motivações internas pelo desenvolvimento de competências, habilidades e atitudes para sanar necessidades profissionais como mais reconhecimento e melhores salários. Nessa perspectiva, os alunos do curso Técnico em Agronegócio têm a oportunidade de desenvolver competências que lhes possibilitarão adotar medidas diferenciadas e inovadoras no meio rural brasileiro.

\section{Conhecendo o Curso Técnico em Agronegócio}

Lançado em 2014, seu principal objetivo é formar profissionais habilitados na análise, na execução e no controle dos procedimentos de gestão e de comercialização do agronegócio, para atuar em empresas e propriedades da agropecuária brasileira. Em 
três anos de operação, foram atendidos mais de 10 mil alunos distribuídos em 98 polos de apoio presencial, localizados em 24 Unidades Federativas. Considera-se uma expansão considerável visto que em 2015 as atividades letivas iniciaram com 954 alunos, distribuídos em 18 polos de apoio presencial, localizados em 8 Unidades da Federação.

Ao todo são realizadas 25 UCs organizadas em um calendário semestral com carga horária total de 1.230 horas, $80 \%$ é realizada a distância, por meio das diferentes tecnologias de informação e comunicação. Os $20 \%$ restantes são dedicados às avaliações presenciais e ao exercício de atividades práticas profissionalizantes, no polo de apoio presencial ou em visitas em propriedades ou empresas rurais, respeitando a legislação vigente quanto à modalidade. Os conteúdos foram selecionados de acordo com a natureza da formação, agrupados por módulos/semestres e organizados na forma de UCs. Para atender à metodologia do curso, e apresentado em três formatos com o propósito de se complementar, aspecto essencial na metodologia adotada: apostila impressa (aprovada no quesito consistência e clareza por $94,7 \%$ dos respondentes da pesquisa de satisfação), videoaulas (aprovadas por 94,7\% dos respondentes, nos quesitos reforço, facilitação, motivação e suficiência), online (aprovado por 92,1\% dos respondentes).

Para operacionalização do curso, as Secretarias Regionais de cada estado da federação e a Coordenação de Tutoria a Distância atuam de modo integrado e conjunto. Cabe às Secretarias Regionais, dentre as suas atribuições, apoiar seus polos presenciais e suas equipes, e à Coordenação de Tutoria a Distância orientar e auxiliar as atividades de tutoria a distância em nível nacional.

Nos polos de apoio presencial do SENAR, os alunos contam com laboratório(s) de informática para atividades do Ambiente Virtual de Aprendizagem (AVA) Acadêmico, acesso ao Sistema de Gestão Educacional (SIGE) e pesquisas online, além de ter sala(s) de aula, de leitura e secretaria. Neste espaço, são desenvolvidas aulas presenciais, plantões de dúvidas, trabalhos em grupo, atividades práticas, avaliações presenciais e interação com tutores presenciais e com os colegas. Ao serem questionados sobre prestatividade, assertividade, facilitação e precisão dos serviços prestados pela tutoria presencial, $94 \%$ dos alunos respondentes avaliaram positivamente, se mostrando satisfeitos.

As atividades a distância ocorrem por meio do Learning Management System (LMS Classe 21). Os alunos têm à disposição, 24 horas por dia, durante todo o período do curso, ferramentas de comunicação, conteúdos no formato digital, videoaulas e 
biblioteca virtual. Por meio do LMS, eles estudam o conteúdo de forma autônoma. São convidados a interagir com colegas e tutores a distância pela ferramenta chat. Refletem, discutem e solucionam situações-problema nos fóruns de discussão, se comunicam com a equipe de tutoria e monitoria por meio da ferramenta tira-dúvidas e mensagens. Realizam também a avaliação a distância, a avaliação diagnóstica e de processos. 0 LMS Classe 21 é considerado um ótimo ambiente de aprendizagem para $97 \%$ dos alunos respondentes. Um dos aspectos fundamentais para a viabilidade da qualidade desse projeto.

O processo de comunicação dos tutores a distância com os alunos ocorre de forma sistemática, personalizada e permanente, desde seu primeiro acesso ao curso até a sua conclusão. Para isso, conta-se com um Plano de Tutoria e Monitoria (PTM) automatizado elaborado com ações de cunho orientativo, informativo e motivacional que tem como principais características a coerência com o período e o desempenho do aluno no curso ou de acordo com a necessidade diagnosticada durante o processo. Esse plano é atualizado a cada semestre, buscando sempre um aprimoramento das ações a partir da análise de dos resultados das turmas anteriores. Esse processo é realizado com a participação da equipe de tutoria a distância e monitoria, sendo conduzido e apoiado pela equipe de coordenação de tutoria a distância. O desempenho do educando é acompanhado diariamente com o propósito de gerar ações estratégicas proativas, ou seja, caso seja diagnosticada alguma necessidade, a equipe de tutoria ou monitoria, sob orientação e apoio da coordenação de tutoria a distância, age com rapidez por meio de ações de cunho orientativo, informativo e motivacional, evitando prejuízos em seu aprendizado e no desempenho no curso.

Além do acompanhamento, os educandos são apoiados e atendidos permanentemente por uma central virtual de tutoria e monitoria, desde o início do curso até sua finalização. A equipe de tutoria, formada por especialistas no conteúdo das UCs, tem o papel de mediar o processo ensino-aprendizagem, propondo chats e fóruns de discussão e também responde às dúvidas de conteúdo no prazo máximo de 24 horas. A equipe de monitoria, tem como principal atribuição primar pelo acesso e utilização das ferramentas do LMS e sanar dúvidas de ordem administrativas. Essa equipe responde às dúvidas e solicitações via ferramenta do LMS em até 4 horas. Para atendimento imediato a dúvidas e dificuldades sobre o acesso e utilização do LMS, os alunos contam ainda com apoio da equipe de monitoria via 0800 , de segunda a sábado, das $8 \mathrm{~h}$ às $21 \mathrm{~h}$ - horário de Brasília. A qualidade dos serviços prestados pela equipe de tutoria e monitoria virtual também é comprovada, visto que $94 \%$ dos respondentes a avaliaram como positiva.

As equipes de monitoria e tutoria a distância são acompanhados permanente pela 
Coordenação de Tutoria a distância, formada por uma equipe de analistas educacionais com conhecimentos pedagógicos e especialistas em EaD. Esta equipe tem como principais atribuições orientar, formar e acompanhar a atuação da tutoria e monitoria junto aos alunos.

A formação inicial dos tutores tem por objetivos desenvolver competências, habilidades e atitudes requeridas para a atuação nas atividades da tutoria a distância, tais como: usar com segurança as ferramentas do LMS, elaborar propostas de fóruns e mediá-los, propor e conduzir discussões nos chats, responder às dúvidas de conteúdo com clareza, objetividade e empatia, elaborar questões para compor os instrumentos avaliativos disponibilizados aos alunos, fazer correções das avaliações a distância com feedbacks construtivos, orientativos e claros. Para atender a esses objetivos, realizam capacitação online no formato de trilha formativa e mediado pela equipe de coordenação de tutoria a distância. Ao concluírem a trilha, os tutores iniciam a atuação como tutores no projeto e inicia-se o processo de formação continuada por meio de acompanhamento permanente e sistemático, realizado pela coordenação de tutoria a distância.

Durante o processo de formação inicial e continuada, prima-se por um processo de comunicação e interação dialógico, horizontal de dupla via, pois assim como Moran (2017), entendemos que novas realidades são criadas a partir de uma comunicação interpessoal, em que a troca nos permite modificar uns aos outros, a realidade à nossa volta e, consequentemente, o contexto em qual vivemos.

\section{Sistema avaliativo e aprovação}

O sistema de avaliação do curso Técnico em Agronegócio compreende avaliação diagnóstica, de aprendizagem e de processos. A avaliação diagnóstica é aplicada no início e no final de cada UC por meio de um questionário digital. Tem como propósito diagnosticar os conhecimentos prévios dos alunos antes de iniciar o estudo e comparar com o aprendizado adquirido no decorrer da UC. Com a análise dos resultados, a gestão faz ajustes ou redefinições na próxima oferta do tema e no curso durante o seu processo operacionalização.

A avaliação de aprendizagem é do tipo formativo e somativo. A avaliação formativa tem por objetivo propiciar a construção de conhecimentos com foco no desenvolvimento das competências, habilidades e atitudes requeridas de um Técnico em Agronegócio formado pelo curso e-Tec SENAR do Brasil. Ocorre ao longo de cada UC e do curso, por meio de atividades presenciais e a distância, sendo que os tutores acompanham o desenvolvimento progressivo do aluno e propõem ações complementares visando à consolidação do processo de aprendizagem. A avaliação somativa é utilizada com o 
intuito de propiciar mudança cognitiva de forma sistemática. Segue as normas do art. $2^{\circ}$ do Decreto no 5.622, de 19 de dezembro de 2005, sendo duas avaliações obrigatórias, uma teórica (Avaliação Presencial Teórica (APT), com peso igual a 40\%) e outra prática (Avaliação Presencial Prática (APP), com peso igual a 30\%) aplicadas presencialmente nos polos, e uma avaliação a distância (Avaliação a Distância (AD), com peso $30 \%$ ). Cada uma das avaliações acontece em um momento diferente, para permitir que o aluno identifique oportunidades de melhoria, principalmente na aplicação prática do conteúdo estudado. Também oferece feedback construtivo e orientativo ao aluno, a fim de valorizar o conhecimento demonstrado, pontuar os aspectos que precisam ser retomados e estimular a continuar, aprofundando seus conhecimentos. Assim como os demais serviços, o processo avaliativo contribui com o aprendizado, pois $95,9 \%$ dos alunos respondentes afirmaram que as avaliações a distância, presencial teórica e prática são relevantes e contribuíram para a aquisição e construção do conhecimento.

Para aprovação na UC, o aluno deverá apresentar frequência mínima, em atividades presenciais e a distância, de $75 \%$. Caso ocorra alguma impossibilidade que impeça 0 aluno de realizar alguma avaliação presencial, poderá fazê-la mediante apresentação de atestado médico, atestado de óbito (membro da família) e declaração de trabalho ou documento equivalente na secretaria do seu polo presencial. Já os alunos que reprovarem em UC cujo somatório total das horas corresponda até o limite de $50 \%$ da carga horária total do semestre letivo têm direito de cursar as UCs de dependência no semestre letivo seguinte à reprovação. Na dependência, mantêm-se as mesmas características da UC regular, isto é, há atividades presenciais e a distância. $O$ aluno reprovado nas UCs em regime de dependência não terá direito a prosseguir para o semestre/módulo seguinte e terá a matrícula cancelada. E ao aluno que possuir o mínimo de $75 \%$ de frequência na UC, além de estar com a Média do Período entre 2,0 e 5,69 , terá direito a fazer uma prova (presencial) no final do semestre letivo. É importante ressaltar que todas as notas e frequência de cada aluno são registradas no SIGE.

E a avaliação de processos é aplicada ao término de cada UC, em que se constitui em pesquisa de satisfação, na qual os alunos podem avaliar o curso e a sua experiência de aprendizagem. A análise dos resultados dessa avaliação permite o aprimoramento das ações realizadas por toda a equipe atuante no projeto.

\section{Considerações finais}

O planejamento, o desenvolvimento e a operacionalização de cursos no formato híbrido/blended learning são um desafio para qualquer instituição. E se tratando da experiência relatada, o desafio é ainda maior para todos os envolvidos no processo ensino-aprendizagem, pois envolve infraestrutura presencial adequada, escolha das 
tecnologias que atendam às especificidades do curso e necessidades do público-alvo, formação da equipe envolvida, processo de comunicação planejado e sistemático entre todos, acompanhamento personalizado e permanente ao aluno, processo de avaliação dinâmico e construtivo e a definição de uma metodologia que norteie e dê sustentação a todos os demais aspectos. Mesmo obtendo um excelente índice (94\%) de aprovação dos alunos com a qualidade dos serviços recebidos ao longo desses três anos, uma prerrogativa da gestão central juntamente com as regionais e coordenação pedagógica, com apoio da equipe multidisciplinar envolvida, é o aprimoramento constante do processo e da operação na oferta do curso Técnico em Agronegócio. Diante do exposto e dos resultados, entende-se que essa experiência pode contribuir como referência de boas práticas para outras instituições atuantes na área de educação a distância, bem como educação técnica de nível profissionalizante.

\section{Referências}

BOIKO, Vanessa A. T.; ZAMBERLAN, Maria A. T. A perspectiva socioconstrutivista na psicologia $\mathrm{e}$ na educação. Disponível em: <http://www.scielo.br/pdf/pe/v6n1/v6n1a07.pdf>. Acesso em: 15 abr. 2018. KNOWLES, M. S.; HOLTON, E. S.; SWANSON, R. A. The adult learner. ButterworthHeinemann, 2012. Disponível em:<https://content.taylorfrancis.com/books/download?da $\mathrm{c}=\mathrm{C} 2011-0-12064-6 \& i s b n=9781136346149 \&$ format=googlePreviewPdf $>$. Acesso em: 15 abr. 2018.

MORAN, José. Metodologias ativas e modelos híbridos na educação. In: YAEGASHI, Solange e outros (Orgs.). Novas tecnologias digitais: Reflexões sobre mediação, aprendizagem e desenvolvimento. Curitiba: CRV, 2017. Disponível em: $<$ http://www2.eca.usp.br/moran/wp-content/uploads/2018/03/Metodologias_Ativas.pdf>. Acesso em: 15 abr. 2018.

As muitas formas de comunicar-nos, 2007. Disponível em: $<$ http://www.eca.usp.br/prof/moran/site/textos/desafios_pessoais/muitas.pdf $>$. Acesso em: 24 abr. 2018.

VALENTE, José Armando. Prefácio. In: BACICH; TANZI NETO (Orgs.). Ensino híbrido: personalização e tecnologia na educação. Porto Alegre: Penso, 2015.

SENAR/Central. Projeto pedagógico de Curso Técnico em Agronegócio a distância. Brasília, 2014. (Documento interno)

SENAR/Central. Pesquisa interna de satisfação do Curso Técnico em Agronegócio SENAR do Brasil. 2017. 